\title{
Medico-legal implications for the colon perforation during colonoscopy
}

\author{
Hae Mi Oh ${ }^{1}$, Jae Myung Cha ${ }^{2}$, Jiyong Park ${ }^{1}$, SuHwan Shin $^{1}$, Danbi Cho ${ }^{1}$, and Sungkyoung \\ $\mathrm{Choi}^{3}$
}

${ }^{1}$ Yonsei University

${ }^{2}$ Kyung Hee University

${ }^{3}$ Yonsei University College of Medicine

October 12,2020

\begin{abstract}
Aims: Colon perforation is the most serious complication of colonoscopy, and tends to be considered as malpractice. The aim of this study was to identify the characteristics and causes of medical accidents by analyzing lawsuit cases on colon perforation during colonoscopy. Methods: We collected judgment results that were ruled from 2005 to 2015 using the keyword of 'colonoscopy' in the 'Korea's Written Judgment Public Reading System' of the Supreme Court, and extracted the cases of colon perforation. Characteristics of medical accidents and the decisions of courts were analyzed from written judgments. Results: Twenty-two lawsuits were analyzed. Most cases were ruled in favor of the plaintiff $(\mathrm{n}=20)$. The allegations against defendants, filed by the plaintiffs, were the performance error $(n=22)$, the improper monitoring after colonoscopy $(n=7)$, and the lack of informed consent $(n=8)$. The median compensation was 9,335.47 US dollar, this is about 130 times the cost of a single colonoscopy in Korea. The greater the intestinal damage, the greater the amount of compensation $(\mathrm{p}=0.016)$. The time interval from procedure to diagnosis of perforation was most frequently 24 hours later $(n=9)$. Conclusions: It is important to educate patients fully about the symptoms of colon perforation and to guide them to contact medical institutions immediately when symptoms occur. In addition, doctors should explain sufficiently the possibility of perforation before colonoscopy to the patients, not caregiver, and get an informed consent.
\end{abstract}

\section{What's already known about this topic?}

Medical accidents can be experienced by any doctor, and especially gastroenterologists are always being exposed to risk of developing perforation during colonoscopy.

\section{What does this article add?}

This is the first study to analyze the characteristics of lawsuit cases of the colon perforation. Most of the lawsuit cases related to colonoscopic perforation were judged in favor of the plaintiff, and the greater the intestinal damage, the greater the amount of compensation. The court declared the doctor's negligence, but reduced liability for damages if appropriate actions were taken.

\section{Introduction}

Colonoscopy, which is one of the most commonly performed gastrointestinal endoscopic procedures, has been used for diagnostic and therapeutic purposes ${ }^{1}$. With the recent rise in colonoscopy screening and the increasing prevalence of colorectal cancer, the use of colonoscopy is steadily increasing worldwide, which also leads to an increase in colonoscopy related complications ${ }^{2,3}$. Colonoscopy is considered relatively safe ${ }^{1,4,5}$, but it can cause complications such as bleeding or perforation, especially in the elderly patients and patients with inflammatory bowel disease ${ }^{2}$. Among colonoscopy-related complications, colon perforation is the most 
serious complication ${ }^{2}$. A recent systematic review of 55 studies reported the risk of perforation during screening colonoscopy as 0.4 per 10,000 case $^{6}$. Kim et al. reported the incidence of colon perforation as 0.5 to 8.5 per 10,000 case. Even though colon perforation rarely occurs, it can lead to serious sequelae such as death or sepsis caused by peritonitis ${ }^{1}$. From the medico-legal perspective, colon perforation often tends to be considered as a doctor's negligence ${ }^{7}$. As a result, doctors may take the defensive attitude of rejecting high-risk patients or passively providing conservative treatment to avoid litigation ${ }^{8-10}$. Review of the medicolegal cases of medical accident can help us prevent similar accidents in the future. From this perspective, written judgments of medical lawsuits on colon perforation may provide useful information to avoid similar accidents. Until now, a few reviews of the cases on the complications of colonoscopy were mostly based on the patient medical records or insurance company records ${ }^{11-13}$, but no studies were based on the using written medical lawsuit judgments. The aim of this study is to identify the characteristics and causes of medical accidents by analyzing lawsuits on colon perforation during colonoscopy.

\section{Materials and Methods}

Data source This study was a retrospective analysis to review all lawsuit cases of colon perforation during colonoscopy using the Court Records of the Republic of Korea ruled from January 2005 to December 2015. We used the keyword of 'colonoscopy' in the 'Written Judgment Public Reading System' provided by the Supreme Court. The courts provided us with the copies of the written judgements deleted personal information. Among the written judgments we collected, the following types of cases were excluded; 1) non-colonoscopy cases, 2) non-perforation cases, 3) non-colon perforation, or 4) cases with insufficient clinical information. When an appeal was made on a case, only the final judgment was included in this study.Study designThe written judgments were reviewed and assessed by two researchers (HM Oh and SH Shin), independently. If the assessments of the two researchers were divergent, they tried to reach common ground through discussion, and if an agreement was not reached, a third researcher (S Choi) additionally analyzed the contents till an agreement was reached. Judicial and clinical information were collected. The judicial information includes type of defendant, the process of lawsuit, the trial outcome, the plaintiff's claim, the claimed amount, and the payment awarded. For the claimed amount and awarded compensation, 1 US Dollar (USD) was converted to 1,165 Korean won based on the average exchange rate in 2019. Clinical information such as the patient's age and sex, indication of colonoscopy, perforation cause and location, the type of surgical treatment, and final outcomes were also collected. In addition, information pertaining to the type of recognition of colon perforation, interventions for perforation, and time elapsed from procedure to diagnosis of perforation were also collected. The diagnosis time point for the colon perforation was defined as the point at which perforation was confirmed with a radiologic examination or a clinical suspicion by a doctor. We divided the patients into three groups according to the degree of contamination in the abdominal cavity, the occurrence of shock, and organ damage using the classification of Flint ${ }^{14}$. Three groups were defined as follows: grade 1 - cases of simple surgery, such as a suture, grade 2 - cases in which the patient had temporary colostomy, and grade 3 cases with cardiopulmonary resuscitation or deep shock events.Statistical analysisData normality was tested with the Shapiro-Wilk test. To compare the three groups based on Flint's classification, the Kruskal-Wallis tests with Bonferroni's correction for multiplicity were performed and considered statistically significant when $\mathrm{p}<0.05$. All statistical analyses were conducted using Microsoft Excel 2013 (Redmond, WA, USA) and IBM SPSS Statistics 25 for windows (Chicago, IL, USA). Ethics statement This retrospective study was approved by the Institutional Review Board in Yonsei University Health System (No. Y-2020-0097) and informed consent was waived.

\section{Results}

In total, 48 lawsuit cases were found through a search of the written judgments. Twenty-six cases were excluded due to being non-colonoscopy cases $(n=2)$, non-perforation cases $(n=18)$, non-colon perforation $(\mathrm{n}=1)$ and cases with insufficient clinical information $(\mathrm{n}=5)$ (Figure 1). Finally, 22 cases were considered for the analysis. Demographics and clinical characteristics are presented in Table 1. The most common perforation location was the sigmoid colon (54.5\%). Perforations occurred most frequently after polypectomy (68.2\%). $40.9 \%$ of perforations were detected by a doctor during colonoscopy, and the rest (59.1\%) were found 
after the patient complained of abdominal pain or hematochezia. Perforations were most often detected 24 hours after colonoscopy $(40.9 \%)$. Thirteen patients $(59.1 \%)$ were transferred to other institutions for optimal management after recognition of perforation. Seventeen $(77.3 \%)$ of the total patients recovered after treatment, while five $(22.7 \%)$ died. Twenty-one patients, except for one patient who died of cardiac arrest after perforation, underwent surgery for perforation treatment. The most common surgeries were simple closure and temporary colostomy with seven patients each. Table 2 presents the detailed nine cases in which perforation was detected 24 hours later after colonoscopy. All nine patients underwent polypectomy, and six of them had symptoms such as abdominal pain, hematochezia, or vomiting 21 to 57 hours after colonoscopy. Two out of nine revisited the hospital after 18 hours or more in spite of the symptom onset (Case 4, 20). For cases 11 and 20, the diagnosis of perforation was delayed because the patients visited the hospital after meals. Two patients had symptoms when they were in the hospital, but the diagnosis was delayed because no perforation was found even in additional colonoscopy or x-ray (Case 5, 15). Table 3 shows the judicial information for all 22 lawsuits. Most cases (95.5\%) were concluded at first trial and $91.0 \%$ were ruled in favor of the plaintiff. The median compensation claimed by plaintiffs was 47,917.83 USD, but the median compensation awarded was 9,335.47 USD, which is a fifth of the median compensation claimed. All plaintiffs made more than one allegation against defendants which were categorized into three groups: performance error $(n=22)$, improper monitoring after colonoscopy $(n=7)$, and lack of informed consent $(n=8)$. Of the eight cases claiming lack of informed consent, five were judged as negligence on the part of the doctor. Four doctors out of the five did not explain the possibility of perforation before colonoscopy, and one explained it to the caregiver, not to the patient. In the case of improper monitoring after colonoscopy, four cases (in which perforation diagnosis was delayed because the patients' complaints of abdominal pain were ignored) and one case (in which no appropriate measures were taken although perforation was suspected during the colonoscopy) were judged as negligence on the part of the doctor. All plaintiffs claimed the perforation occurred due to the doctor's performance error, but the courts did not judged it as the negligence of the doctor in four cases. In addition, for 13 cases, the courts declared doctor negligence but reduced the liability for damage. The most common reason of extenuating circumstances was the doctor's quick and appropriate response to perforation (Figure 2). Table 4 shows data comparing the three groups based on Flint's classification. Ten patients were classified as Grade 1. Grade 2 included seven patients, and Grade 3 included five. There was no statistically significant difference in the time elapsed from procedure to diagnosis of perforation between the three groups $(p=0.102)$. Patients in Grade 2 experienced a longer time lapse from procedure to diagnosis of perforation than those in Grade 3 who had severe colon damage. The difference in the compensation between the groups was statistically significant $(\mathrm{p}=0.016)$ and, as a result of Bonferroni Correction, the groups with significant differences were Grade 1 and Grade 3. The median compensation for Grade 3 was 4.6 times higher than that of Grade 1. As a result of analyzing the loss of earning capacity affecting the indemnity for damages (Table 5), '100\% loss of the remaining lifespan' was recognized in all cases where the patient died $(n=5)$. On the other hand, when the patient recovered, there were various court's decisions regardless of the type of surgery the patients received. Among them, ' Not recognized of loss of labor ability' was the highest with seven cases.

\section{Discussion}

Colon perforations are inherent in the performance of colonoscopy, which may raise a medicolegal problem. As far as we know, this study is the first one to analyze characteristics of lawsuit cases of colon perforation caused by colonoscopy using the Court Records. The most important finding of the current study is that lawsuit cases of colon perforation during colonoscopy are characterized by 1) colon perforation detected 24 hours later after colonoscopy, 2) decision in favor of the plaintiffs in most cases, and, in particular, the worse the patient's condition, the higher the compensation, and 3) not all cases recognized as malpractice despite of an obvious colon perforation. In general, perforation is detected within a few hours after colonoscopy, but perforation symptoms may develop after several days, especially in the case of a therapeutic procedure ${ }^{15-17}$. In addition, when the size of the perforation is small, symptoms may not appear for several days ${ }^{18,19}$. In this study, there were nine cases of delayed perforation, and symptoms of suspected perforation appeared up to 57 hours after colonoscopy. Since perforation can occur at any time in up to seven days after colonoscopy ${ }^{20-22}$, 
delayed perforation may not be noticed by a close monitoring, such as a short hospitalization. Therefore, thorough patient education for the possible symptoms of colon perforation after procedure may be the best way to detect a missed perforation. The median compensation was 9,335.47 USD, this is about 130 times the cost of a single colonoscopy in Korean primary clinic (with a one-time charge of about 72.66 USD as of 2020). The more severely damaged the colon, the higher the compensation. However, it is impossible to judge the severity of malpractice simply by the amount of compensation, because the compensation is calculated by taking into consideration the patient's age and income levels, mental damage and limitation of liability. Compensation covers medical expenses, damages due to loss of earning capacity, and consolation money for mental damage. We found that the types of loss of earning capacity varied regardless of which surgery the patient underwent or the patient outcome, except when the patient died. In Korea, 'Disability Evaluation of McBride' are used when determining the loss of earning capacity ${ }^{23}$, but this standard, created in the 1960s, does not adequately reflect the current situation and is limited in that the doctor's subjective opinion or judgment may have an influence. Consolation money for mental damage is also judged entirely in accordance with the discretion of the court ${ }^{24}$. In this study, it can be seen that the level of consolation money varies (See the supplementary table). In Korea, in the case of traffic accidents, the court set the standard for consolation mone ${ }^{25}$, but there is no standard in medical accidents. Therefore, for the court's consistent and fair judgment on medical accidents, it is necessary to improve the criteria for consolation money and loss of earning capacity and to regard the nature of medical practices such as the possibility of force majeure medical accidents. Perforation is an obvious medical accident. In this study, $91 \%$ case was decided in favor of the plaintiff. However the courts did not judge every case as a doctor's performance error. In general, it is known that doctors need to meet a minimum standard of colonoscopy experience to ensure the quality of colonoscopies ${ }^{26,27}$. However, even the most skilled doctors may not avoid colon perforation ${ }^{28}$, and some people are skeptical of requiring for minimal standards of colonoscopy experience ${ }^{29,30}$. It was found that judges considered how doctors responded after recognizing the perforation or whether there was any cause on the part of the patient, rather than the doctor's competency. In addition, sometimes, courts regarded perforation as an unavoidable complication of colonoscopy. Therefore, doctors can reduce the liability for damages in a lawsuit as much as possible by responding appropriately and immediately after recognizing perforation. However, since colonoscopy is often performed in primary $\operatorname{clinic}^{3,20}$, it is not easy to immediately treat perforation in their clinic. Therefore, it is necessary for medical institutions to establish an emergency transfer system. Since informed consent is the best way to ensure patient autonomy and protect doctors from dispute, it is important to both parties ${ }^{31}$. Based on the trust between the doctor and the patient, the doctor must fully explain the possibility of perforation to the patient and let the patient self-determine whether to undergo colonoscopy despite such risks ${ }^{32}$. Sufficient time is required for informed consent. Colonoscopy is rarely performed urgently, so it is not impossible to devote sufficient time to informed consent before testing. However, it is never easy to establish a doctor-patient relationship, since colonoscopy is mainly performed in a short time at an outpatient clinic $^{3,20}$. Doctors and patients may neglect the informed consent because of people's perception that the colonoscopy is safe ${ }^{33}$. However, patients tend to sue when trust building with doctor fails ${ }^{34,35}$. In addition, lack of informed consent is the main reason for the medical litigation ${ }^{36}$. In the process of informed consent, the doctor should explain this to the patients, not their family members. In this study, there was a case in which a doctor, who explained the possibility of perforation to a patient's family members, was judged as violating doctor-patient confidentiality. Obtaining consent from the patient's family members is clearly a violation of the patient's autonomy ${ }^{37}$ and does not conform to the purpose of the informed consent. In this context, we suggest that doctors explain and obtain consent for polypectomy and biopsy together when explaining colonoscopy to all patients. If doctors did not get a written consent before colonoscopy, a polyp, which is unexpectedly encountered during colonoscopy cannot be removed because it is virtually impossible to obtain immediate consent from the patient being examined. This study has some limitations. First of all, it was difficult to perform rich and in-depth analysis because detailed clinical information was not provided in the lawsuit and there were many missing data. In addition, the total number of cases is small and therefore the generalizability of the results is limited. In fact, when a medical accident occurs, not all patients sue. Since medical disputes are often settled through negotiation between patients and doctors, it is hard to say that this study, using lawsuit cases, represents the status of colon perforation 
accidents during colonoscopy. Nevertheless, it is significant that this study has been analyzed from a medical and legal point of view, with a clear focus on the subject of colon perforation caused by colonoscopy.

\section{Conflict of Interests}

The authors declare that they have no conflict of interest.

\section{Funding}

The authors received no specific funding for this study.

\section{References}

1 Mai CM, Wen CC, Wen SH, et al. Iatrogenic colonic perforation by colonoscopy: a fatal complication for patients with a high anesthetic risk. Int J Colorectal Dis. 2010;25:449-454.

2 Kim SY, Kim H-S, Park HJ. Adverse events related to colonoscopy: Global trends and future challenges. World journal of gastroenterology. 2019;25:190-204.

3 Cha JM, Kwak MS, Kim HS, et al. Real-world national colonoscopy volume in Korea: a nationwide population-based study over 12 years. Gut and liver. 2020;14:338-346.

4 Avgerinos DV, Llaguna OH, Lo AY, et al. Evolving management of colonoscopic perforations. Journal of Gastrointestinal Surgery.2008;12:1783-1789.

5 Lo AY, Beaton HL. Selective management of colonoscopic perforations. Journal of the American College of Surgeons. 1994;179:333-337.

6 Whitlock EP, Lin J, Liles E, et al. Screening for colorectal cancer: an updated systematic review. 2008;65.

7 Gerstenberger PD, Plumeri PA. Malpractice claims in gastrointestinal endoscopy: analysis of an insurance industry data base. Gastrointestinal endoscopy. 1993;39:132-138.

8 Panella M, Rinaldi C, Leigheb F, et al. Prevalence and costs of defensive medicine: a national survey of Italian physicians. Journal of health services research $\&$ policy. 2017;22:211-217.

9 Reisch LM, Carney PA, Oster NV, et al. Medical malpractice concerns and defensive medicine: a nationwide survey of breast pathologists. American journal of clinical pathology. 2015;144:916-922.

$10 \mathrm{Xu}$ X, Spurr SJ, Nan B, et al. The effect of medical malpractice liability on rate of referrals received by specialist physicians. Health economics, policy, and law. 2013;8:453-475.

11 Conklin LS, Bernstein C, Bartholomew L, et al. Medical malpractice in gastroenterology. Clinical Gastroenterology and Hepatology.2008;6:677-681.

12 Hernandez LV, Klyve D, Regenbogen SE. Malpractice claims for endoscopy. World J Gastrointest Endosc. 2013;5:169-173.

13 Rabeneck L, Paszat LF, Hilsden RJ, et al. Bleeding and perforation after outpatient colonoscopy and their risk factors in usual clinical practice. Gastroenterology. 2008;135:1899-1906.

14 Flint LM, Vitale GC, Richardson JD, et al. The injured colon: relationships of management to complications. Annals of surgery.1981;193:619-623.

15 Xiao Y-F, Bai J-Y, Yu J, et al. Endoscopic treatment of delayed colon perforation: the enteroscopy overtube approach. Endoscopy.2014;46:503-508.

16 Lüning T, Keemers-Gels M, Barendregt W, Tan A, Rosman C. Colonoscopic perforations: a review of 30,366 patients. Surgical endoscopy.2007;21:994-997.

17 O'BRIEN T, Garrido M, Dorudi S, Collin J. Delayed perforation of the colon following colonoscopic biopsy. British journal of surgery.1993;80:1204. 
18 Cho SB, Lee WS, Joo YE, et al. Therapeutic options for iatrogenic colon perforation: feasibility of endoscopic clip closure and predictors of the need for early surgery. Surgical endoscopy.2012;26:473-479.

19 Christie JP, Marrazzo J. "Mini-perforation" of the colon — not all postpolypectomy perforations require laparotomy. Diseases of the colon $\mathcal{E}$ rectum. 1991;34:132-135.

20 Ranasinghe I, Parzynski CS, Searfoss R, et al. Differences in colonoscopy quality among facilities: development of a post-colonoscopy risk-standardized rate of unplanned hospital visits. Gastroenterology. 2016;150:103-113.

21 Rabeneck L, Saskin R, Paszat LF. Onset and clinical course of bleeding and perforation after outpatient colonoscopy: a population-based study. Gastrointestinal endoscopy.2011;73:520-523.

22 Levin TR, Zhao W, Conell C, et al. Complications of colonoscopy in an integrated health care delivery system. Annals of internal medicine. 2006;145:880-886.

23 Feffer HL. Disability Evaluation and Principles of Treatment of Compensable Injuries. JAMA. 1964;188:89.

24 Hyeon CW, Lee W, Kim SY, et al. Prevention of medical malpractice and disputes through analysis of lawsuits related to coronary angiography and intervention. The Korean Journal of Internal Medicine.2020;35:605-618.

25 JRT I. Measures for calculating appropriate consolation money for each type of negligence. 2017:1-10.

26 Min JK, Cha JM, Kwak MS, et al. Quality Indicators and Outcome Measures of Endoscopy in the National Cancer Screening Program. Yonsei medical journal. 2019;60:1054-1060.

27 Segnan N, Patnick J, Von Karsa L. European guidelines for quality assurance in colorectal cancer screening and diagnosis : Publications Office of the European Union; 2010.

28 Rex DK. Advice Regarding Reduction of Malpractice Risk in Colonoscopy. Gastroenterology 83 Hepatology. 2006;2:212-216.

29 Lieberman D, Nadel M, Smith RA, et al. Standardized colonoscopy reporting and data system: report of the Quality Assurance Task Group of the National Colorectal Cancer Roundtable. Gastrointestinal endoscopy. 2007;65:757-766.

$30 \mathrm{Ko}$ CW, Riffle S, Michaels L, et al. Serious complications within 30 days of screening and surveillance colonoscopy are uncommon. Clinical Gastroenterology and Hepatology. 2010;8:166-173.

31 Feld KA, Feld AD. Risk management and legal issues for colonoscopy. Gastrointestinal endoscopy clinics of North America.2010;20:593-601.

32 Waye JD, Rex DK, Williams CB. Colonoscopy: Principles and Practice. Hoboken. NJ: J Wiley; 2003:55-62.

33 Yom-Tov E, Lebwohl B. Adverse events associated with colonoscopy; an examination of online concerns. BMC gastroenterology.2019;19:207-213.

34 Vincent C, Phillips A, Young M. Why do people sue doctors? A study of patients and relatives taking legal action. The Lancet.1994;343:1609-1613.

35 Tucker JD, Cheng Y, Wong B, et al. Patient-physician mistrust and violence against physicians in Guangdong Province, China: a qualitative study. BMJ open. 2015;5:1-10.

36 Hiyama T, Tanaka S, Yoshihara M, et al. Medical malpractice litigation related to gastrointestinal endoscopy in Japan: a two-decade review of civil court cases. World Journal of Gastroenterology: WJG. 2006;12:6857-6860.

37 Jarayedi Z, Asghari F. From whom do physicians obtain consent for surgery? Journal of medical ethics. 2018;44:366-370. 
Table 1. Demographics and clinical characteristics of study population

\begin{tabular}{|c|c|}
\hline Demographics and clinical characteristics & Demographics and clinical characteristics \\
\hline Age (yr), mean (range) & Age (yr), mean (range) \\
\hline \multirow[t]{4}{*}{ Sex, $\mathrm{n}(\%)$} & Sex, $\mathrm{n}(\%)$ \\
\hline & Male \\
\hline & Female \\
\hline & Not identified \\
\hline \multirow[t]{6}{*}{ Location of colon perforation, n (\%) } & Location of colon perforation, n (\%) \\
\hline & Sigmoid colon \\
\hline & Descending colon \\
\hline & Transverse colon \\
\hline & Ileocecal valve \\
\hline & Not identified \\
\hline \multirow[t]{3}{*}{ Main cause of perforation, n (\%) } & Main cause of perforation, n (\%) \\
\hline & With polypectomy \\
\hline & Without polypectomy \\
\hline \multirow[t]{3}{*}{ Time elapsed from procedure to diagnosis of perforation, $\mathrm{n}(\%)$} & Time elapsed from procedure to diagnosis of perforation, \\
\hline & $\begin{array}{l}\text { Immediately by doctor (during procedure) } \\
\text { Within } 24 \text { hours }\end{array}$ \\
\hline & $24-72$ hours \\
\hline \multirow[t]{3}{*}{ Interventions for colon perforation, $\mathrm{n}(\%)$} & Interventions for colon perforation, $\mathrm{n}(\%)$ \\
\hline & Transfer to other institution for optimal management \\
\hline & Treatment at the institution (defendant) \\
\hline \multirow[t]{5}{*}{ Type of surgical treatment the patient received, $\mathrm{n}^{+}$} & Type of surgical treatment the patient received, $\mathrm{n}^{+}$ \\
\hline & Simple closure \\
\hline & Temporary colostomy \\
\hline & Segmental resection \\
\hline & Not identified \\
\hline \multirow[t]{3}{*}{ Final clinical outcomes after perforation, n (\%) } & Final clinical outcomes after perforation, n (\%) \\
\hline & Recovery after treatment \\
\hline & Death \\
\hline
\end{tabular}

+ One case that the patient died of cardiac arrest after perforation was excluded.

Table 2. The detailed nine cases in which perforation was detected 24 hours later after colonoscopy

\begin{tabular}{llll}
\hline Case no & Time elapsed $(\mathrm{hrs})$ & Time elapsed $(\mathrm{hrs})$ & Time elapsed (hrs) \\
\hline & From colonoscopy to perforation diagnosis & From colonoscopy to symptom onset & From symptom onset to th \\
4 & 43.5 & 24.5 & $19++$ \\
5 & 30.5 & 0 & Not applicable \\
8 & 25.5 & 21.5 & $0 \$$ \\
10 & 62.5 & 57 & 5.5
\end{tabular}




\begin{tabular}{llll}
\hline Case no $^{+}$ & Time elapsed (hrs) & Time elapsed $(\mathrm{hrs})$ & Time elapsed (hrs) \\
\hline 11 & 72 & 51 & 6 \\
15 & 65 & 7.5 & $0 \S$ \\
17 & 35 & 31 & $0 \mathbb{1}$ \\
20 & 32.5 & 7 & 18 \\
22 & 54.5 & 46 & 3 \\
\hline
\end{tabular}

+ Refer to the supplementary table

++ The patient called the hospital immediately after onset of symptoms, but the staff ignored the patient's complain.

$\S$ The patient was in the hospital.

I The patient visited the emergency room immediately after onset of symptoms.

Table 3. Judicial characteristics of 22 lawsuits

\begin{tabular}{lll}
\hline Judicial characteristics & Judicial characteristics & Results \\
\hline Type of defendant, n (\%) & Type of defendant, n (\%) & $9(40.9)$ \\
& Physician only & $9(40.9)$ \\
& Physician and medical institution & $4(18.2)$ \\
Process of lawsuit, n (\%) & Medical institution only & $21(95.5)$ \\
& Process of lawsuit, n (\%) & $1(4.5)$ \\
Trial Outcome, n (\%) & First instance & \\
& Final appeal & $20(91.0)$ \\
& Trial Outcome, n (\%) & $1(4.5)$ \\
Compensation claimed (USD) & Ruled in favor of plaintiff & $1(4.5)$ \\
& Settlement decision & $47,917.83(30,362.55-8$ \\
Compensation awarded (USD), n (\%) & Dismissal & $9,335.47(6,837.46-21$, \\
& Compensation claimed (USD) & $5(22.7)$ \\
& Median (IQR) & $16(72.7)$ \\
& Compensation awarded (USD), n (\%) & $1(4.6)$ \\
Type of plaintiff's claim against defendants, n & Median (IQR) & Type of plaintiff's claim against defendants, n \\
& $>30,000$ & 22 \\
& Performance error & 7 \\
\end{tabular}

USD $=$ United States Dollar; IQR = Interquartile range (Q1-Q3)

The exchange rate was $1 \mathrm{USD}=1,165$ Korean Won

+ All plaintiffs made more than one allegation against defendants. Three cases included all three types of claims, and nine included two types.

Table 4. Time elapsed from procedure to diagnosis of perforation and awarded compensation in each group 


\begin{tabular}{|c|c|c|c|}
\hline Group & Time elapsed from procedure to diagnosis of perforation $(\mathrm{hr})$ & & Awarded compe \\
\hline Grade $1(n=10$, death $n=0)$ & $0(0-6.1)$ & $P=0.102^{*}$ & $7,378.80(6,83$ \\
\hline Grade $2(\mathrm{n}=7$, death $\mathrm{n}=0)$ & $35(24.3-49)$ & & $8,583.69(4,77$ \\
\hline Grade $3(\mathrm{n}=5$, death $\mathrm{n}=5)$ & $4(0-32.5)$ & & $34,573.05(34,3$ \\
\hline
\end{tabular}

$\mathrm{USD}=$ United States Dollar; the exchange rate was $1 \mathrm{USD}=1,165$ Korean Won

Data are presented as median values along with interquartile range (Q1-Q3).

* Kruskal-Wallis non-parametric test

** Bonferroni Correction. Significant differences between Grade 1 and Grade 3 ( $P=0.003)$

Table 5. Types of the loss of earning capacity recognized by the court

\begin{tabular}{lc}
\hline Type of loss of earning capacity & Patient's \\
\hline & Recovery \\
& Temporar \\
Not recognized & 2 \\
$100 \%$ loss of only the hospitalization period & 2 \\
$100 \%$ loss of the remaining lifespan & 0 \\
$13 \%$ loss of the remaining lifespan & 1 \\
$100 \%$ loss of the hospitalization period and 50\% loss of the period from the first discharge to colostomy closure & 1 \\
$15 \%$ loss of the period from the hospitalization to full recovery (6 months) & 0 \\
Total + & 6 \\
\hline
\end{tabular}

+ Of all 22 cases, a dismissal case was excluded.

Figure legends

Figure 1. Flow chart of the search protocol

Figure 2. Reason of extenuating circumstances in allegations regarding doctor's performance error.

This analysis contains 16 lawsuits. One out of 17 cases was excluded because of insufficient information. Nine cases of these include two or more reasons.

+ old age, obesity, high blood pressure, general weakness due to other diseases, history of abdominal surgery, ulcerative colitis, smoking, and etc. 


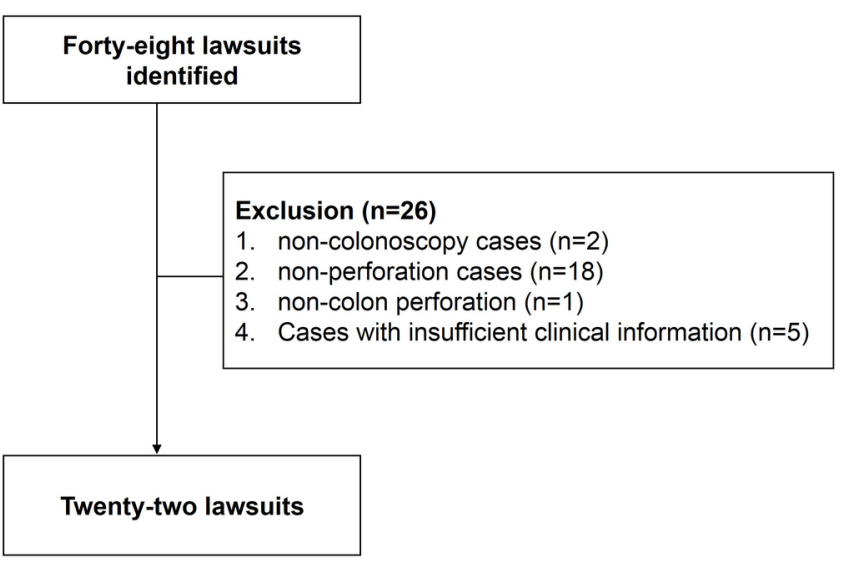

The patient did not follow the doctor's instructions

It was a delayed perforation

The patient fully recovered

The patient had a risk factor for causing perforation ${ }^{a}$

Perforation is a complication that can always occur

The doctor responded quickly to the perforation 